\title{
Microwave resonator method of dynamic measurement of mass of the samples of gasifying solid fuel
}

\author{
Victor V. Perov ${ }^{1}$, and Vladimir. E. Zarko, ${ }^{1, *}$ \\ ${ }^{1}$ Voevodsky Institute of Chemical Kinetics and Combustion, 630090 Novosibirsk, Russia
}

\begin{abstract}
The paper describes novel contactless method of determining instantaneous gasification rate of solid materials under intensive blowing the reacting (gasified) surface. Method is based on dynamic measurement of the mass of dielectric substance within specially designed microwave resonator. The attenuation of passing through the resonator signal is proportional to the actual value of the sample mass. Before firing experiments the setup is calibrated using samples of studied material with different channel radius. With the proper choice of data acquisition system one can achieve the web sample thickness resolution around few microns and time resolution higher than $1 \mathrm{kHz}$. The examples of preliminary tests with paraffin samples blown by air jets with temperatures of 350-1500 K and speeds of $375-700 \mathrm{~m} / \mathrm{s}$ are presented.
\end{abstract}

\section{Problem statement}

Existing microwave techniques are intended for exploring the linear burning rate of energetic material (EM) samples [1]. They are based on registration of amplitude and phase of the microwave signal passing through a sample and reflected from the burning surface of solid fuel at the expense of sharp change of dielectric properties on the interface of between the fuel and air. Known techniques do not allow investigating the dynamic gasification processes of bored samples of solid fuel at intensive blowing the channel surface.

\section{Microwave sensor}

To achieve the specified goal the microwave resonator method of dynamic measurement of mass of gasifying solid fuel samples has been developed based on the measurement of the attenuation of a microwave signal passing through the resonator sensor [2] (Fig. 1) loaded with investigated sample.

*Corresponding author: zarko@kinetics.nsc.ru 


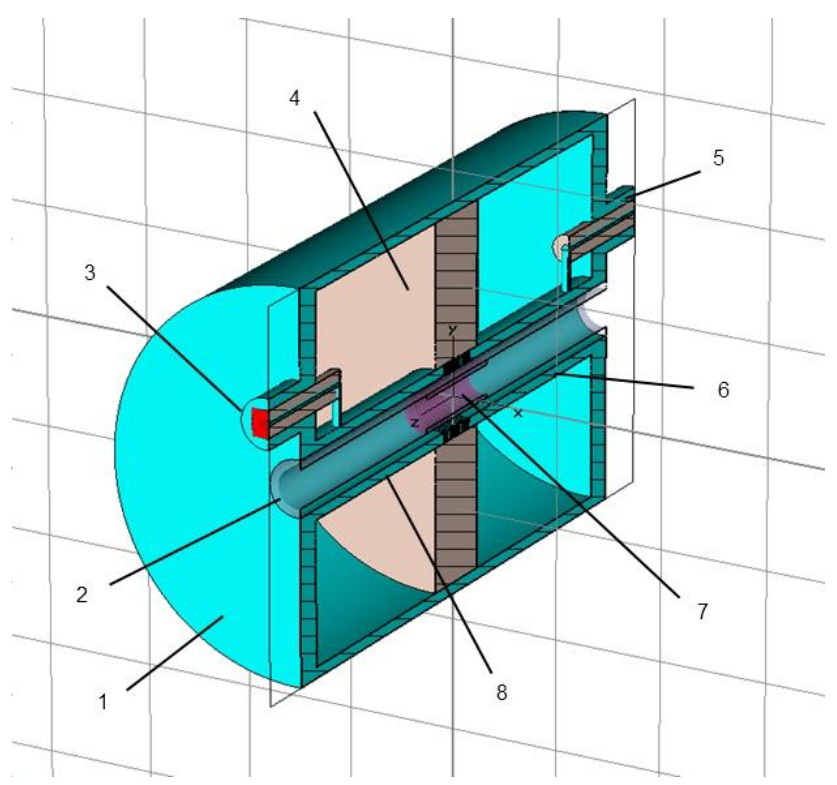

Fig 1. The microwave sensor.

1 - case; 2 - protective tube; 3 - input port; 4 - centering disk; 5 - output port; 6 - output resonator; 7 - sample; 8 - input resonator.

The sensor is executed in the form of system of two connected coaxial resonators excited on antiphase type of fluctuations through one of two ports. Another port is intended for passing the microwave signal to the receiver of the network analyzer. The working area of the sensor is formed by a gap between coaxial resonators. For achievement of the highest uniformity of distribution of high-frequency electric field in the volume of studied sample the length of working area is chosen equal to its diameter.

When carrying out researches, the resonant characteristic of the sensor is previously determined and change of transitional attenuation S21 between sensor's ports on the chosen working frequency is controlled. Insertion of a sample of solid fuel into working area of the sensor affects the form of the resonant characteristic. The first change of the characteristic is connected with the shift of resonant frequency of an antiphase type of the fluctuations, which is caused by increase in magnitude of connection between coaxial resonators at the expense of insertion of dielectric material. If the EM formulation includes the boron powder possessing considerable losses on ultrahigh frequencies, the resonant characteristic S21 (f) except shift also extends because of deterioration of the quality (Q-factor) of the system of connected resonators on the antiphase type of fluctuations.

\section{Sensor calibration}

Before firing experiments the sensor is calibrated by means of samples of studied material having different channel radius (Fig. 2). Let's note a high linearity of the calibration characteristic S21 (r) in the field of radiuses of 4-8 $\mathrm{mm}$ owed to a special design of the sensor and an optimum selection of working frequency that allows minimizing the number of calibration samples up to one sample of studied material. In this case the second point in the calibration characteristic is determined in the absence of EM material in the working area of sensor. 


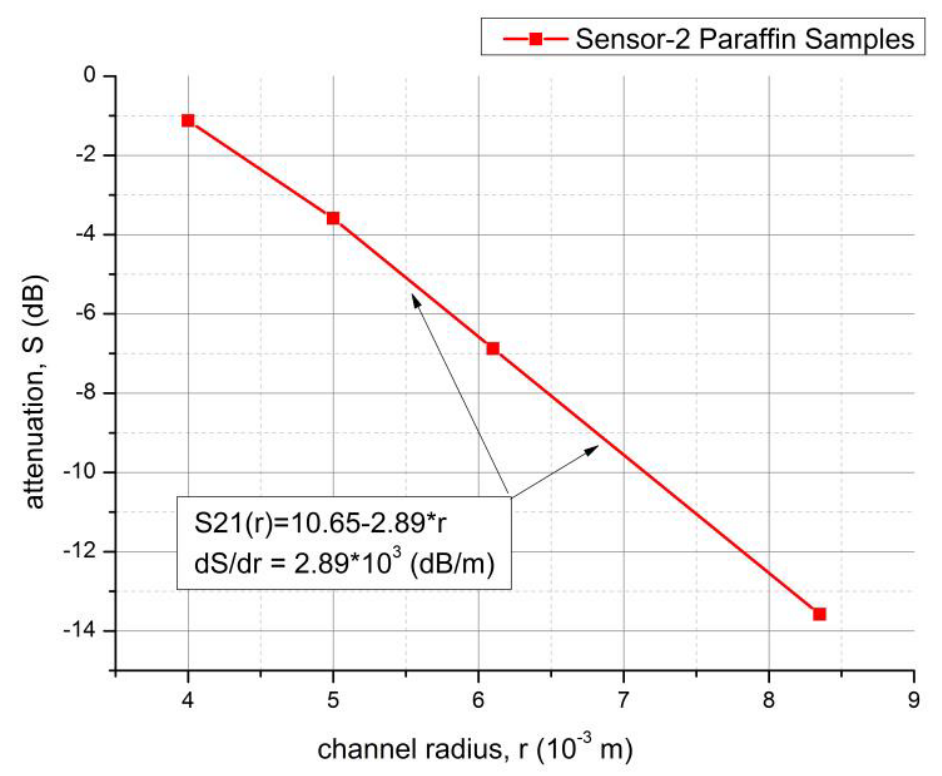

Fig 2. Dependency of the passing microwave signal attenuation on the working frequency versus the channel radius of calibrated samples made of $\mathrm{P}-2$ paraffin.

Calibration curve $\mathrm{S}(\mathrm{r})$ in the case of paraffin samples is characterized by an inclination angle of $\mathrm{dS} / \mathrm{dr}$ equaled $2.89 \cdot 10^{3} \mathrm{~dB} / \mathrm{m}$. Applying this result together with the results of registration of gasification of paraffin samples in the form of $S(t)$ (Fig. 3), we can obtain the required dynamic $\mathrm{dr} / \mathrm{dt}$ parameters for each concrete experiment.

\section{Experiments}

The microwave resonator method of dynamic mass measurement of solid fuel samples has been illustrated [3] on an example of research of gasification process of the paraffin samples blown by a high speed jets of hot air (Fig. 3, 4). 


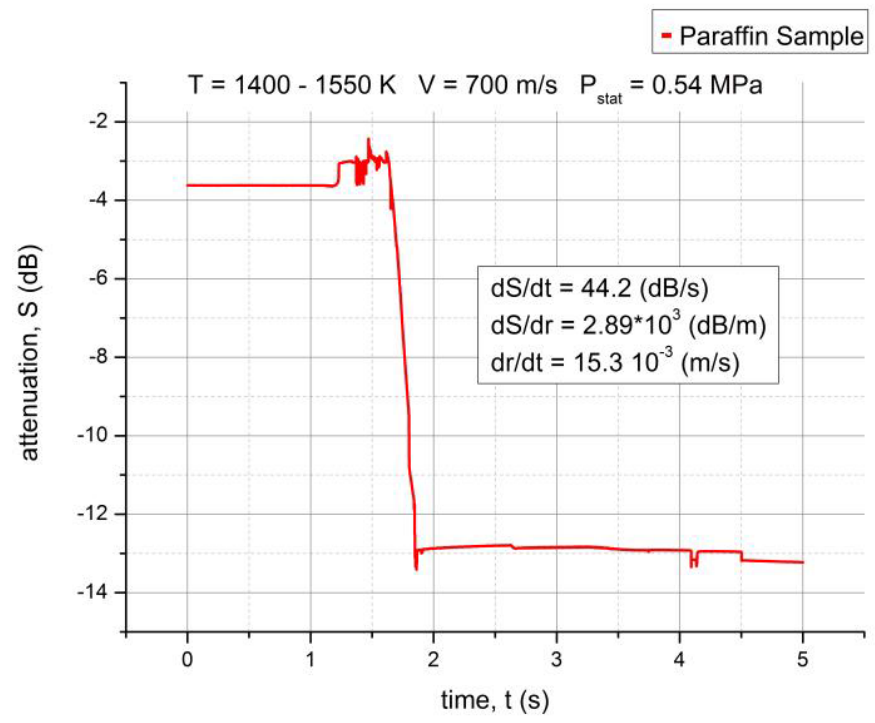

Fig. 3. Dependency $S(t)$ upon paraffin gasification by the air jet with parameters: jet speed $V=700$ $\mathrm{m} / \mathrm{s}$, temperature $\mathrm{T}=1300 \mathrm{~K}$, static pressure $\mathrm{P}_{\text {stat }}=0.54 \mathrm{MPa}$.

Duration of gasification process is $0.23 \mathrm{~s}$. Speed of change of the channel radius in the middle of the process is $15 \cdot 10^{-3} \mathrm{~m} / \mathrm{s}$.

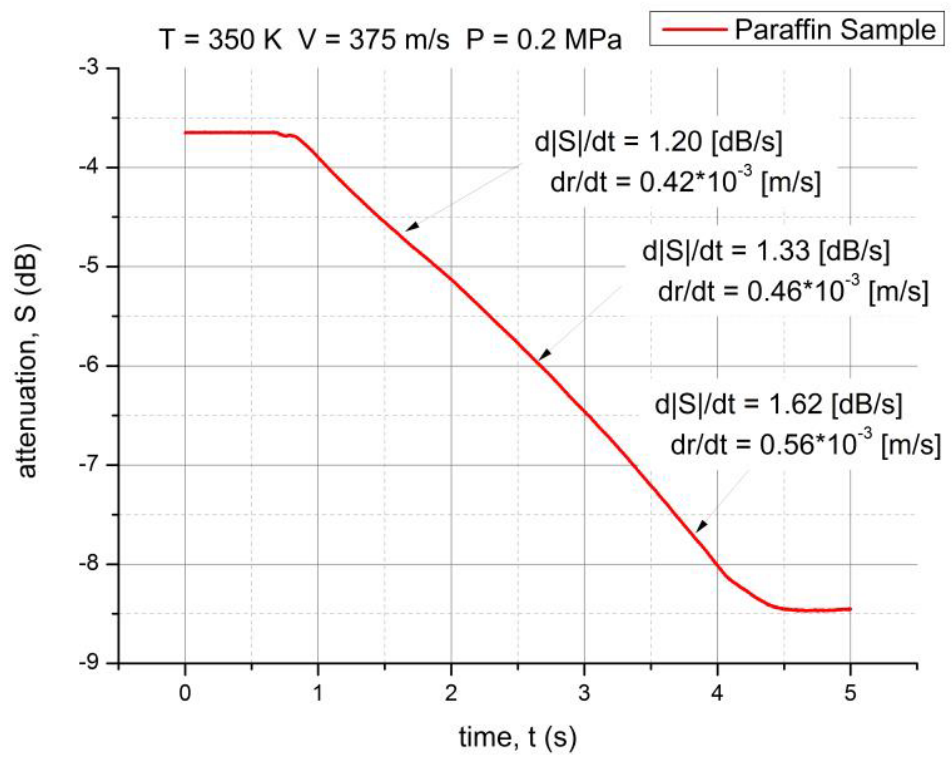

Fig. 4. Experimental dependency $\mathrm{S}(\mathrm{t})$ in the case of paraffin $\mathrm{P} 2$ sample gasification by the air jet with the speed of $375 \mathrm{~m} / \mathrm{s}$, temperature $350 \mathrm{~K}$ and gas static pressure $0.2 \mathrm{MPa}$.

Duration of gasification process is $3.7 \mathrm{~s}$. Speed of the channel radius changing during gasification process increases from $0.42 \cdot 10^{-3} \mathrm{~m} / \mathrm{s}$ to $0.56 \cdot 10^{-3} \mathrm{~m} / \mathrm{s}$.

As a material of samples the P-2 type paraffin has been chosen. The rate of gasification equals to $15.1 \cdot 10^{-3} \mathrm{~m} / \mathrm{s}$ at blowing by air jet with temperature of $1300 \mathrm{~K}$ and speed of 700 
$\mathrm{m} / \mathrm{s}$ and it is about $0.5 \cdot 10^{-3} \mathrm{~m} / \mathrm{s}$ at blowing by air jet with temperature of $350 \mathrm{~K}$ and speed of $375 \mathrm{~m} / \mathrm{s}$.

The sample studied is fixed on a sensor axis by two tubes. Internal diameter of tubes is equal to initial diameter of the channel in a studied sample that allows providing uniform velocity profile of a gas stream at the sample entrance.

The registration area of the gasification process is determined by the length of the sensor working zone that allows excluding side areas of a studied sample from consideration and reliably determining the result caused by the gasification process of a sample central region.

\section{Conclusions}

Thus, the method described allows measuring the instantaneous gasification rate of the samples of dielectric materials under intensive gas blowing with the space resolution about few microns and time resolution better than $1 \mathrm{kHz}$. The method can be used to obtain the dependencies of gasification rate on the parameters of gas blowing and to study different dynamic gasification regimes at varying in time conditions of solids gasification.

This work was partially supported by the Russian Foundation for Basic Research (project number 16-29-01029).

\section{References}

1. D.A.Yagodnikov, A.V. Sergeyev, V. V. Koziche, Combust. Explos. Shock Waves 50, $2(2014)$

2. V. V. Perov, V.E. Zarko, A.S. Zhukov, Combust. Explos. Shock Waves 50, 6 (2014)

3. V.V. Perov, V.E. Zarko, V.I. Zvegintsev, D.G. Nalivaichenko, Proceedings of 56th Israel Annual Conference on Aerospace Sciences (WeL2T5.3. Haifa, Israel, 2016) 